\title{
Erratum to: Relations of osteoporosis and follow-up duration to recurrent falls in older men and women
}

\author{
M.-R. Lin • H.-F. Hwang • P.-S. Lin • C.-Y. Chen
}

Published online: 21 November 2013

(C) International Osteoporosis Foundation and National Osteoporosis Foundation 2013

\section{Addendum to: Osteoporos Int}

DOI 10.1007/s00198-013-2549-5

The author is pleased to supply the acknowledgements, inadvertently omitted from this article:

Acknowledgements This work was funded by the National Health Research Institute (NHRI-EX101-9805PI) and the National Science Council (NSC100-2314-B-038-025), Taiwan, ROC.

The online version of the original article can be found at http://dx.doi.org/ 10.1007/s00198-013-2549-5.

M.-R. Lin $\cdot$ H.-F. Hwang $\cdot$ C.-Y. Chen

Institute of Injury Prevention and Control, College of Public Health

and Nutrition, Taipei Medical University, Taipei, Taiwan

H.-F. Hwang

Department of Nursing, National Taipei College of Nursing,

Taipei, Taiwan

P.-S. Lin

Department of Physical Therapy and Rehabilitation Science,

Chang Gung University, Guishan, Taoyuan, Taiwan

M.-R. Lin $(\triangle)$

Institute of Injury Prevention and Control, Taipei Medical University, $250 \mathrm{Wu}-H$ sing Street, Taipei 110, Taiwan

e-mail: mrlin@tmu.edu.tw 